\title{
(Re)Examining the Non-Use of ICT
}

\section{Catherine Kellner, Luc Massou and Pierre Morelli}

Translator. Inist

\section{OpenEdition}

\section{Journals}

Electronic version

URL: http://journals.openedition.org/questionsdecommunication/8884

DOI: 10.4000/questionsdecommunication.8884

ISSN: 2259-8901

\section{Publisher}

Presses universitaires de Lorraine

\section{Printed version}

Date of publication: 1 December 2010

ISBN: 978-2-8143-0056-9

ISSN: 1633-5961

\section{Electronic reference}

Catherine Kellner, Luc Massou and Pierre Morelli, «(Re)Examining the Non-Use of ICT », Questions de communication [Online], 18 | 2010, Online since 01 February 2014, connection on 30 April 2019. URL http://journals.openedition.org/questionsdecommunication/8884 ; DOI : 10.4000/ questionsdecommunication.8884

This text was automatically generated on 30 April 2019.

Tous droits réservés 


\title{
(Re)Examining the Non-Use of ICT
}

\author{
Catherine Kellner, Luc Massou and Pierre Morelli \\ Translation : Inist
}

\section{EDITOR'S NOTE}

This English translation has not been published in printed form/Cette traduction anglaise n'a pas été publiée sous forme imprimée.

1 With the surge in the use of information technology and communication, non-users of ICT can be considered to be more than just a simple anomaly, especially where the Internet is concerned. Recent studies have shown the existence of a 'plateau effect', a slowdown in the growth of Internet users in developed countries since 2002 (Chia, Li, Detenber and Lee, 2006: p. 589-609), and even a stagnation in the proportion of nonInternet users from one year to another (Smith, 2010). While this rate obviously reflects the existence of a hard core of non-users, we know that members of this fringe group can nevertheless become users in the more or less long term (Chia, Li, Detenber and Lee, 2006: p. 590-591). Conversely, we are also aware that users may, for one reason or another, temporarily or regularly revert to being non-users. In both Anglo-Saxon and French scientific literature, the question of the non-use of ICT is rarely treated as an issue in its own right. Rather, it is considered either as a special case of use or, more commonly, as a lack of use. However, the reasons behind the non-use of ICT are sufficiently complex to indeed justify treating this practice as an issue in its own right.

Given the spread of Internet connections in the West, one of the main questions is therefore to understand the motivations and factors that explain this persistent non-use of ICT. As this special issue will show, the status of non-user sometimes reflects a principled stand taken by the individuals concerned (rejection of modernity and the supremacy of technology, resistance to change, etc.), resulting from a deliberate choice, openly asserted or demanded. However, we will also discuss the emergence of other factors that render the mapping and the relationship between use and non-use much more complex. 


\section{Beyond the digital divide}

Professor Sally Wyatt of the Royal Netherlands Academy for Arts and Sciences is internationally known for the pioneering role she has played in researching the very meaning of non-use. This subject had previously been considered as a shortcoming and a problem to be solved, at the risk of generating social, political and economic exclusion. Basing her work on founding English-language texts, Wyatt stresses the turning point taken by studies into the use of technology over the last fifteen years. Since 1999, her research has contributed to the modification of the status of non-users of ICT and the ways in which they are portrayed. Drawing on the writings of James E. Katz and Philip Aspden (1998), Wyatt points to the gradual emergence of a 'less visible' social group that opens up new perspectives for studies on the different uses of ICT. Indeed, discussing the subject of the non-use of ICT within the context of a literary review results in references dealing more specifically with the 'digital divide', a much more commonly used term than 'non-use' or 'non-users'.

4 Moreover, in an article on the sociologies of the digital divide, published in the French journal Questions de communication, Fabien Granjon (2004: p. 217-232) proposes a critical review of this concept, which he considers reflects a new inequality that it is essential to curb as quickly as possible if we are not to witness a widening of the 'social divide' (ibid., p. 218). Granjon notes that the injunction to become a user is strongly present, particularly where official discourse and policy are concerned. He therefore identifies three main categories of studies on the digital divide and the use of the Internet: infrastructure approaches, the socialisation of the Internet, and the forms of appropriation and the reproduction of social relations. The first category refers to issues of land-use planning and the equipment of households and institutions. The second focuses on studies that take into account the identity of users (primarily neophytes or first-time users) in their everyday environments. Finally, the third category focuses on the mechanisms that determine the 'updating of uses' (ibid., p. 225). Anglo-Saxon literature is full of scientific articles related to this concept. Similar to the observation made by Granjon, these studies predominantly raise the issue of non-use in terms of conditions of access to ICT, through the technical, financial and socio-educational resources required to facilitate their use or that explain their non-use. This approach is still very present ${ }^{1}$, the main objective of recent studies on the subject being to identify levers to define future policies for increased ICT use by people from certain social backgrounds. Even today, Granjon notes that the primary objective of the quantitative data available is to help categorise non-use, but in too partial a way. Indeed, he deplores the fact that very few researchers analyse non-use as a more or less militant act of resistance, not just as a shortcoming or as an indication of new inequalities.

Since 2006, the very concept of the digital divide has been challenged by Neil Selwyn (2006: p. 273-292), Mike Cushman and Ela Klecun (2006: p. 347-364), and Jochen Peter and Patti M. Valkenburg (2006: p. 293-305). Selwyn considers that this concept needs to be reevaluated, given that it no longer exists for those users who tend to 'log off' when they feel they have 'consumed' too much technology. However, this same concept becomes more meaningful for other users given its persistence in developed or developing countries, especially within certain disadvantaged or excluded social groups. In all cases, Selwyn believes that the users/non-users dichotomy is too crude and superficial to finely 
analyse disparities in engagement with new technologies. The resolving of access issues would not necessarily lead to actual use. Moreover, non-users do not fall into a homogeneous group. This fact led Sally Wyatt (2002) and Katherine Allen et al. (2003) to identify different categories of non-users, ranging from the total non-user to the minimalist user who voluntarily limits or even abandons his/her use of ICT. Selwyn recommends paying more attention to the social circumstances that lead to this abandoning of the use of ICT (choice, inequality, motivation), and to this end focuses on bottom-up research (from the specific to the general). This stand has been adopted by all of the contributors who have undertaken qualitative analyses in the field. Peter and Valkenburg (2006: p. 294) advocate a 'digital differentiation' approach to replace that of the digital divide, because they believe the former attributes greater importance to the characteristics of the Internet itself, rather than the characteristics of the actual users. Digital differentiation is based on the principle of social determinism, where the Internet plays both a social and a political role, preventing rather than gridlocking inequalities in order to avoid depriving part of the population of their autonomy. The impact of the socio-economic, cultural and cognitive resources of users should therefore be taken into account to identify potential differences in the use of the Internet. Finally, Cushman and Klecun (2006: p. 348) suggest replacing the term 'digital divide' with that of 'digital exclusion', to better assess the complex nature of the processes involved in understanding the use and non-use of ICT. According to these authors, the concept of social exclusion can be used to explain digital exclusion. The social context of the actors involved, whether or not they are users of ICT, must therefore be taken into consideration. Engagement with new technologies would thus depend on a contextual framework created by these individuals and their motivation to use ICT, not considered as an end in itself, but as a step towards achieving a goal, accomplishing a task, or bringing about a change in their everyday lives. Digital exclusion is therefore both a constituent part and a result of social exclusion when taken as a set of resources available to the social actors and including their social, educational and cultural capital (ibid., p. 352). Among the factors of non-use identified in Cushman and Klecun's study, it is mainly the inability to imagine the variety of potential uses and the lack of knowledge of Internet tools that prevent the fulfilment of a project of use by the social actors encountered. For them, a project of this nature is primarily one of interpersonal communication (with family and friends) and the carrying out of certain tasks of everyday life. Lack of knowledge of the tools is therefore a key factor leading Cushman and Klecun to consider Fred D. Davis's famous theoretical Technology Acceptance Model (1989) as inadequate for analysing non-use. This inadequacy is due to the fact that the model assumes sufficient familiarity with ICT on the part of the users and fails to take account of users as social actors. In his article devoted to the sociologies of the digital divide, Granjon (2004: p. 223) cites the work of Benoit Lelong (2003: p. 116) for whom this research has the advantage of showing that lower living standards or a lower educational capital do not systematically involve less frequent or less sophisticated practices. As Lelong explains, such research endeavours to place attitudes within identity and relational perspectives, anchoring them in ingrained habits and concrete situations, restoring the rationality of both use and non-use rather than attributing the relative underutilisation of ICT to a lack of competence or principled resistance to new technologies.

6 It is on this last point that these various researchers agree: no longer thinking only in terms of divide where ICT access and skills are concerned, but reconsidering non-users as 
social actors. The states of the art suggested by the authors of this special issue also clearly demonstrate this particular position attributed to non-use, very often seen as a deficit, a shortcoming, or a cultural and social injustice, as yet another struggle in the fight against the digital divide. The contributions to this special issue therefore all abandon this concept of the digital divide as a focus area in favour of a more detailed analysis of real-life situations that are too complex to be explained by a Manichean approach of users versus non-users.

\section{Taking account of non-users in their social context}

7 Neil Selwyn's study (2006) shows that socio-demographic factors such as age, gender or socio-economic background have only a limited impact on the use or non-use of ICT. These factors were most commonly observed among the strict non-users who were, moreover, the least numerous of the sample analysed ( $8 \%$ of a total of 1,001 respondents). While the three main factors of non-use were primarily the lack of need, interest and motivation with regard to ICT, the interviews highlighted the importance of the fact that technological objects did make sense in the daily lives of the respondents. Where the low users were concerned, it was common for them to go through intermediaries (relatives, spouses, colleagues or children) to use ICT. Selwyn's results are similar to those that we present in this special issue, and also reflect the results of other important quantitative studies, notably those that have been carried out by the Pew Internet \& American Life Project in the United States since 2002 on the adoption of broadband Internet by the American population. In a study carried out in 2009, based on a sample of 2,253 respondents interviewed by phone or online, $21 \%^{2}$ declared that they did not use the Internet (Horrigan, 2009). Half of the respondents claimed that the main reason behind their non-use was a lack of interest in using the Internet, which they considered irrelevant to their daily lives. Other criteria included cost, availability and usability (ease of use). Despite the fact that $48 \%$ of the non-users came from underprivileged backgrounds (annual incomes of less than US $\$ 20,000$ ), the study showed that the financial criterion was not the main reason for non-use. Their socio-demographic profile did, however, clearly indicate a link between non-use and level of education, with $77 \%$ of respondents having either not finished high school or not moved on to further education. This confirms the conclusion of the study by Mike Cushman and Ela Klecun (2006) into digital exclusion, which postulates that the lack of use among non-users can be explained by the lack of knowledge of Internet tools. An interesting extension of this study by the Pew Internet \& American Life Project was suggested in a report on the National Broadband Plan released by the Federal Communications Commission (FCC) in September $2009^{3}$. This report suggested carrying out further studies on these non-Internet users in the United States ${ }^{4}$, in particular taking into account their attitudes and the impact of their personal environments (contacts, homes, etc.). Similar results were found in studies on non-users in Europe, notably the comparative approach by Sylvia E. Peacock and Harald Künemund (2007: p. 191-200) to the specific European senior citizens demographic group. Using data from the Eurobarometer 59.2 (published in $2003^{5}$ ), this study places lack of interest and lack of home computer as the main factors explaining non-use. It also identifies factors more directly related to the environment of the people concerned, referring to two 'developmental lags' that produce an area of 'social tension' among European senior citizens (ibid., p. 192): 'individual lags' (when the technological 
environment changes more rapidly than people's abilities) and 'structural lags' (a mismatch between the changing capabilities of senior citizens and the structures of modern societies). On the question of attitudes and behaviours among non-users of ICT, two recent studies (Verdegem and Verhoest, 2009; Verkasalo et al., 2010), referring to the most commonly used theoretical models in international research on the acceptance of ICT $^{6}$, have confirmed the importance of the 'relative utility' or perceived usefulness of a product in relation to the emotional, cognitive and material resources of an individual (Verdegem and Verhoest, 2009: p. 644). In this way, non-use may be explained by a negative attitude towards ICT, as well as the perceived lack of pleasure or 'behavioural control' (Verkasalo et al., 2010: 251) that reflects a desire to control the use of certain technological tools. Only the impact of social norms on individuals is not taken into account in these two studies, the latter referring to the work of Richard P. Bagozzi (2007) on the influence of social identity, i.e., the feeling of belonging to a group or community, connoted positively or negatively depending on the individual.

8 Several studies recognise the importance of the issue of 'ordinary sociability' (Granjon, 2004: p. 223) or the 'sociology of everyday life' (Boutet and Trémenbert, 2009: p. 98) that we find at the heart of the article by Panayiota Tsatsou on the context in Greece. These studies accept stabilised systems of use, which are both numerous and sophisticated (Granjon, 2004: p.226), and to a certain extent reach the same conclusion as our qualitative study of certain education and counselling professions in the social sector (Kellner, Massou and Morelli, 2010), in which we suggest considering non-users or limited users as a category in their own right. For Tsatsou ${ }^{7}$, it is a case of understanding the lack of adoption of the Internet in Greece in terms of everyday life. Historical factors, which still heavily influence Greek culture today, would seem to be at the origin of the observed non-use. Resistance to innovation is, according to the author, particularly present in modern Greek society. This resistance stems from a rich cultural and socio-economic history that partly explains the lack of civic spirit and of civic and social conscience that many researchers from different disciplines have noted in Greece and analysed as a drift towards individualism. Catherine Kellner, Luc Massou and Pierre Morelli also take into account the personal and professional background of respondents in order to understand situations of limited use or of non-use. Factors include the influence of the respondents' environment, the more or less porous boundaries between the private and professional spheres, the importance of contact persons or intermediaries, and the impact of personal and professional values. In her study on the search for medical information, Sally Wyatt (2010) demonstrates how the choices of individuals tend to be rooted in the moral economy of the household, in social and cultural relations, as well as in the relations of production. Together, these factors allow for extending the analysis of the role of non-use or of low use of the Internet in what Granjon (2004: p. 227) refers to as the (re)definition of social dynamics, in the sense that ICT constitutes active elements organising the relations of men among themselves and with their environment (Akrich, 1987: p. 49).

\section{Non-use as an issue in its own right}

9 Annabelle Boutet and Jocelyne Trémenbert (2009: p.70) describe three current approaches in the identification of indicators of this 'digital exclusion': ignoring nonusers as a category in their own right in studies (which is akin to recognising the domination of a 'super-category' of users); regarding these non-users as a homogeneous 
whole (a 'catch-all' category that ignores very heterogeneous situations or experiences); and constructing typologies that objectify the intentions declared by the actors themselves. Offering a critical review of bibliographic resources on the use of ICT, these authors state the need to invent a 'sociology of non-use' to offset a 'negative' appearance (ibid., p. 73-74) of non-users in studies, notably statistical studies based on questionnaires that do not allow for analysing the systems of representation and perception of the respondents. To justify taking into account the diversity of situations of non-use and putting them into perspective with respect to individuals and their activities, Boutet and Trémenbert (2009) refer to Sudha Ram's model of resistance to innovation (1987). This model emphasizes the importance of compatibility between the innovation and the values, experiences and needs of the consumer, i.e., his/her personality traits. Within this framework, the case study carried out by Boutet and Trémenbert between 2004 and 2008, in an area consisting mainly of social housing, centred on the identification of explanatory and structuring factors behind the non-use of the Internet and computers. Based on interviews, a participatory survey and participatory observation, their study identifies six main factors, some of which we also find here: family circle, technological environment, access to ICT, experience and skills in the use of ICT, time and priority management, support requirements when using ICT (Tsatsou; Kellner, Massou and Morelli). To extend their work, Boutet and Trémenbert suggest several avenues that have largely inspired this special issue, notably treating non-use as the result of a conscious decision, discussing experience in technical objects to identify logics of non-use (Boutet and Trémenbert, 2010: p.96), and listening to what non-users have to say about their 'non-practice' (ibid., p. 97).

Moreover, all of the contributors agree on the necessity of going beyond the simplistic dichotomy that qualifies the use of the Internet as being graduated between recognised users, on the one hand, and potential users (or 'not yet' users), on the other. According to some researchers, non-users of technology in general and, more specifically, the Internet should at a minimum be considered a social group in their own right (Wyatt, 1999; Wyatt, Thomas and Terranova, 2002), and one that can wield a certain influence given that nonuse is anything but a trivial singularity in the surge of ICT that affects us all. That being the case, it can reveal a state of mind (temporary or permanent), resistance to any form of injunction to use, a desire to be (or to once again become) master of our own choices. The five contributions to this special issue therefore place the non-use of ICT at the heart of each of their premises, establishing it as an issue in its own right that does not fall within a perspective of the development towards use. As Fabien Granjon explains here, refining typologies allows for going beyond this simplistic view and for understanding how the non-use of ICT can actually meet other requirements, such as those found in some of the cases studied by Corinne Martin and Thilo von Pape, Panayiota Tsatsou, or Catherine Kellner, Luc Massou and Pierre Morelli. For example, Martin and von Pape have shown that the fact of not owning a mobile phone is not so much the consequence of some kind of impossibility (financial, for example), and even less the result of an inability to adapt to this technical object, but rather a deliberate choice and therefore a clearly stated and assumed refusal (2010). Nevertheless, for Granjon, some non-uses of technologies may also represent the expression of a kind of self-preservation against certain forms of humiliation associated with the use of unfamiliar and poorly mastered technical tools. Kellner, Massou and Morelli have also identified - among education and counselling professionals in the social sector - moments of use that tend to be confined to 
either the personal or the professional sphere and result from deliberate choices. In the vast majority of cases, limited use is a result of a conscious decision and justified by a rationality that respondents are perfectly able to explain. The non-users we are dealing with here are therefore not victims of some sort of digital divide. But neither is it a case, contrary to what one might expect, of militant acts on the part of hard-core technophobes. Given this premise, the authors identify a rational use of ICT, adapted to the professional and personal needs of the individuals interviewed.

\section{Convergence and complementarity between methodological approaches}

Beyond the stated results (see above), the main contribution of Neil Selwyn's work (2006) was to follow up a major quantitative approach with a qualitative approach. As pointed out by Josiane Jouët (2000: p. 514), this allows for avoiding the statistical generalisation so common in Anglo-Saxon studies and therefore identifies the meaning of communicative acts and the social purpose of the use of ICT within specific social groups. From this point of view, Selwyn's quantitative study allows for attributing a more macro-social dimension to this use: socio-demographic variables, segmentation, and drivers of change. Corinne Martin and Thilo von Pape also propose a similar methodological structure and seek closer collaboration between these two approaches to improve the understanding of the significance of communication objects in the social sphere (Jouët, 2000: p. 514). Sally Wyatt, Fabien Granjon, Corinne Martin and Thilo von Pape also point out the limitations of a purely quantitative scientific approach to the non-use of ICT. Indeed, quantitative statistical analysis based on telephone or online surveys of large samples of the population (Chia, Li, Detenber and Lee, 2006; Lin, 2006; Livingstone and Helsper, 2007) allows for identifying certain generic factors in whether or not a new technology is adopted, and propose a typology. Andrew J. Flanagin (2000), for example, has classified the likelihood of adoption of a corporate website by 288 companies according to three categories of factors: organisational (information flow, communication, dependence on ICT access conditions, institutional pressures, etc.); social (perceived benefits, social pressure at inter-organisational level, social impact, etc.); and behavioural (attitude towards ICT, perception of acceptance in others, perception of control, etc.). Only qualitative approaches allow for studying the complexity and interdependence of these different factors. Similarly, the diversity of reasons for non-use, combined with the difficulty of tracking non-users, introduces serious methodological problems which have led Wyatt to focus on qualitative studies. She recommends shifting the focus of research away from professional use to ordinary daily practices. This would allow researchers to free themselves from the case of 'powerful actors' (scientists, engineers, politicians, financial actors), and thus deviate from functionalist and positivist views in favour of a real study into the meaning of non-use. Wyatt presents main lines of future research on the basis of studies she published in 1999 and 2000, completing them with an empirical study on the use or non-use of the Internet by senior citizens residing in South East England. These persons are faced with age-related health issues that do not necessarily require immediate action; they therefore have plenty of time to search for useful information. In the same way, the combined approach between quantitative and qualitative studies by Martin and von Pape highlights the heuristic value of this complementarity. Like Granjon, these two authors (French and German, respectively) 
provide a summary of the fundamental work carried out into this issue of the use and non-use of ICT, and more specifically of mobile phones. This contribution allows for going beyond the strict limits of computer technologies. Information and communication sciences tend not to publish in international journals. And yet this is very useful for comparing the complementary nature of French and foreign approaches. Martin and von Pape's contribution lies in confronting and comparing two scientific aspects, corresponding to different research traditions, and two fields of study. In keeping with traditional French approaches, Martin carried out two studies using semi-structured interviews. The first study concerned 20 French families and their teenagers, and sought to identify their perceptions of mobile phones. In the second study, 12 French students were interviewed about their use or non-use of the photo and video functions of their mobile phones. Meanwhile, from a more Anglo-Saxon perspective, von Pape drew on work concerning the spread of technological innovations to address, using a quantitative approach, the issue of the ownership of mobile phones by students across 16 high school classes in Germany. By comparing their results and methods, the authors discuss the limitations of each approach and demonstrate the heuristic value of their complementarity.

Mobilising a qualitative approach based on four focus groups, each with six participants, Panayiota Tsatsou postulates the importance of the relationships between the information society and cultural heritage on the choice of use or non-use of ICT. To this end, she concentrated her study on the Greek society today. Her results are compared with a previous quantitative survey conducted with 1,000 users and non-users. The approach is remarkable: based on the results of the previous quantitative analysis, Tsatsou examines the complexity of social divides through the study of the views expressed and the 'meaningful interactions' objectified through these focus groups. Similarly, taking advantage of a qualitative approach, Catherine Kellner, Luc Massou and Pierre Morelli chose to conduct a thorough analysis through semi-structured interviews of 13 professionals from the social sector, working in education (special needs and early childhood educators) and in marriage and family counselling. The communication practices of these professionals are rarely studied. Revealing the reasons for the use of ICT by this group - which tends to be limited - is a first step, the heuristic value of which remains, nevertheless, perfectible. For this reason, the study attempted to shed light on other issues, notably the convergence of five factors that cropped up during the course of the interviews: needs, skills, representations, values, and background/environment. By analysing the interaction of these five factors, the authors have been able to explain several reasons for the limited use of ICT within this group.

\section{Conclusion}

Scientific positioning and the choice of specific methodologies allow these researchers to draw new lines of research. Fabien Granjon suggests problematizing the non-use of ICT using Axel Honneth's theory of recognition (2000). As such, non-use would be a form of response to the ideological recognition conveyed by the mythology of the information society. Granjon's analysis of the views of non-users allows him to suggest a critical analytical perspective which would not consider representations and practices as opposing factors (ibid.). It is his opinion that we can gain a much richer and very different understanding of the practices (or non-practices) of the actors involved by taking into 
account the social meanings that emerge when users, whatever their frame of mind, are confronted with the socio-technical guidelines inherent in new technologies. Catherine Kellner, Luc Massou and Pierre Morelli, however, in their study on the limited use of ICT by certain social workers, place these factors at the centre of the analysis by seeking to take into account the specificity of a profession that falls within very specific social representations and structures, as well as the individual and professional attitudes of the actors interviewed. These main results refine the category of non-users that Granjon refers to as 'low users', highlighting different levels and moments of use. Once again, Granjon moves away from a prescriptive, bipolar view, to consider future quantitative studies based on these explanatory factors. Picking up the thread of research undertaken in the late 1990s - in other words, well before we started down the road of information society development policies - Sally Wyatt demonstrates that non-use is far from being an absence of practice that requires decoding. Examining use on the grounds of its absence tends to bias research. It is therefore necessary to consider use as a practice that is neither 'normal' nor 'taken for granted', but rather heterogeneous and complex, falling within situations depending on choices that are or can be contextualised. Addressing non-use as a subcategory of use prevents the researcher from falling into the trap of conventional certainties, and the research from being restricted to ideologies underlying political and economic rationales. To structure and refine research into this subject, Panayiota Tsatsou advocates adopting a mixed approach where qualitative research is used to analyse the consistency and nature of quantitative results. Corinne Martin and Thilo von Pape, by their comparative approach to the non-use of mobile phones, also demonstrate the value of comparing these two approaches. Their epistemological reflections generate new understandings based on a logic of the hybridisation of two methods that should be developed within a multidisciplinary and international scientific context for the qualitative approach to gain recognition, on the one hand, and the quantitative analysis to become more refined, on the other.

Finally, after exploring the existing situation, these contributions suggest another way of problematizing a still relatively little-researched topic, whose main value is to astutely and efficiently discuss the complexity of the polymorphous and balanced non-use of ICT.

\section{BIBLIOGRAPHY}

Ajzen I., 1991, " The theory of planned behavior ", Organizational Behavior and Human Decision Processes, 50(2), pp. 179-211.

Akrich M., 1987, « Comment décrire les objets techniques », Techniques et culture, 9, pp. 49-64.

Allen K., Boyce A., Horrigan J., Lenhart A., Madden M., O'Grady E., Rainie L., 2003, « The EverShifting Internet Population:A new look at Internet access and the digital divide ", Pew Internet \& American Life Project. Accès: http://www.pewinternet.org/Reports/2003/ The-EverShiftingInternet-Population-A-new-look-at-Internet-access-and-the-digital-divide.aspx. Consulté le 06/07/10. 
Bagozzi, R. P., 2007, « The legacy of the Technology Acceptance model and a Proposal for a Paradigm Shift », Journal of the Association for Information Systems, 8(4), pp. 244-254.

Boutet A.,Trémenbert J., 2009, « Mieux comprendre les situations de non-usages des TIC. Le cas d'Internet et de l'informatique. Réflexions méthodologiques sur les indicateurs de l'exclusion dite numérique ", Les Cahiers du Numérique, 1(5), pp. 69-100.

Chia C. S., Li H., Detenber B., Lee W., 2006, « Mining the internet plateau: an exploration of the adoption intention of non-users in Singapore », New Media@Society, 4(8), pp. 589-609.

Cushman M., Klecun E., 2006, « How (can) nonusers engage with technology: Bringing in the Digitally Excluded », pp. 347-364, in: Trauth E., Howcroft D., Butler T., Fitzgerald B., DeGross J., eds, Social Inclusion: Societal and Organizational Implications for Information Systems, Boston, Springer.

Davis F. D., 1989, « Perceived Usefulness, Perceived Ease of Use, and User Acceptance of Information Technology », MIS Quarterly, 13(3), pp. 319-340.

Dlodlo N, 2009, « Access to ICT education for girls and women in rural South Africa: a case study », Technology in society, 31, pp. 168-175.

Fishbein M., Ajzen, I., 1975, Beliefs, attitude, intention and behavior: an introduction to theory and research, Reading, MA:Addison-Wesley.

Flanagin A. J., 2000, « Social pressures on organizational Website adoption », Human Communication Research, 4(26), pp. 618-646.

Granjon F., 2004, « Les sociologies de la fracture numérique. Premiers jalons critiques pour une revue de la littérature », Questions de communication, 6, pp. 217-232.

Honneth A., 2000, La lutte pour la reconnaissance, trad. de l'allemand par P. Rusch, Paris, Éd. du Cerf, 2008.

Horrigan J., 2009, « Home Broadband Adoption 2009 », Pew Internet Research \&American Life Project. Accès : http://www.pewinternet.org/Reports/2009/10-Home-Broadband- Adoption-2009.aspx. Consulté le 09/12/09.

Jouët J., 2000, « Retour critique sur la sociologie des usages », Réseaux, 100 (18), pp. 487-521.

Katz J. E., Aspden P., 1998, « Internet dropouts in the USA », Telecommunications Policy,4/5 (22), pp. 327-339.

Lelong B., 2003, «Quel “fossé numérique” ? Clivages sociaux et appropriation des nouvelles technologies », pp. 112-116, in : Maigret É., dir., Communication et médias, Paris, Documentation française.

Lelong B., Thomas F., Ziemlicki C., 2004, « Des technologies inégalitaires ? L'intégration d'internet dans l'univers domestique et les pratiques relationnelles », communication au congrès international TIC \& Inégalités : les fractures numériques, 18-19 nov., Paris. Accès : http:// irene.asso.free.fr/digitaldivides/papers/LELONG.pdf. Consulté le 28/06/10.

Lin C. A., 2003, « An interactive communication technology adoption model », Communication Theory, 4(13), pp. 345-365.

Livingstone S., Helsper E., 2007, « Gradations in digital inclusion: children, young people and the digital divide », New Media@Society, 4(9),pp. 671-696.

Peacock S. E., Künemund H., 2007, « Senior citizens and Internet technology. Reasons and correlates of access versus non-access in a European comparative perspective ", European Journal of Ageing, 4, pp. 191-200. 
Peter J.,Valkenburg P. M., 2006, « Adolescents' internet use:Testing the "disappearing digital divide" versus the "emerging digital differentiation" approach ", Poetics, 34, pp. 293-305.

Ram S., 1987, « A model of innovation resistance », Advances in Consumer Research, 14, pp. 208-212. Rogers E. M., 1962, Diffusion of innovations, NewYork, The Free Press, 2003.

Selwyn N., 2003, « Apart from Technology: Understanding People's Non-Use of Information and Communication Technologies in Everyday Life », Technology in Society, 25, pp. 99-116.

- 2006, « Digital division or digital decision ? A study of non-users and low-users of computers », Poetics, 34, pp. 273-292.

Smith A., 2010, « Home Broadband 2010 », Pew Internet \& American Life Project. Accès : http:// www.pewinternet.org/Reports/2010/Home-Broadband-2010.aspx. Consulté le 03/09/10.

Verdegem P., Verhoest P., 2009, « Profiling the non-user: rethinking policy initiatives stimulating ICT acceptance », Telecommunications Policy, 33, pp. 642-652.

Verkasalo H., López-Nicolás C., Molina-Castillo F. J., Bouwman H., 2010, « Analysis of users and non-users of smartphone applications », Telematics and Informatics, 27, pp. 242-255.

Wyatt S., 1999, « They came, they surfed, they went back to the beach: why some people stop using the internet », conference Society for Social Studies of Science, San Diego. Accès : http:// virtualsociety.sbs.ox.ac.uk/reports/surf.htm. Consulté le 10/07/08.

Wyatt S., Thomas G., Terranova T., 2002, « They came, they surfed, they went back to the beach: Conceptualizing Use and Non-Use of the internet », pp. 23-40, in: Woolgar S., ed., Virtual society? Technology, Ryberhole, Reality, NewYork, Oxford Press Inc.

\section{NOTES}

1. See, for example, the article by Nomusa Dlodlo (2009: p.168-175) published in Technology in Society. Dlodlo's case study examines access to ICT education for girls and women in rural South Africa, taking into account the socio-economic environment and identifying several barriers to use: a shortage of specialist teachers, lack of ICT policies, the attitude of the women with regard to technical subjects, level of education, access to tools and electricity, and the role of African women in the family.

2. Visit the project website: http://www.pewinternet.org/ for more information. Consulted 08/12/09.

3. Access: http ://reboot.fcc.gov/open-meetings/2009/september. Consulted 08/12/09.

4. In this respect, it is interesting to note that the proportion of $21 \%$ of non-users is further confirmed in the study 'Home Broadband 2010' issued on 11th August 2010 on the Pew Internet Project website. Access: http://www.pewinternet.org/Press-Releases/2010/HomeBroadband-2010.aspx. Consulted 03/09/2010.

5. Access: http :// www.esds.ac.uk/findingData/snDescription.asp?sn=4837. Consulted 03/09/2010.

6. 'Diffusion of Innovations' by E. Rogers $(1962,2003)$, the Theory of Reasoned Action by M. Fishbein and I. Ajzen (1975), the Technology Acceptance Model by Fred D. Davis (1989), and the Theory of Planned Behaviour by I. Ajzen (1991). For a summary definition of these four models, see: http://edutechwiki.unige.ch/fr/Théorie_de_la_diffusion_de_l \%27innovation. Consulted 09/12/2009. 
7. While Tsatsou still uses the term 'digital divide' to situate the level of ICT development in Greece within the European socio-economic environment, it is not, in her opinion, responsible for the causes of the non-use of these technologies, which are primarily cultural and historical.

\section{AUTHORS}

\section{CATHERINE KELLNER}

Centre de recherche sur les médiations

(Mediation Research Centre)

Université Paul Verlaine-Metz

kellner@univ-metz.fr

\section{LUC MASSOU}

Centre de recherche sur les médiations

Université Paul Verlaine-Metz

massou@univ-metz.fr

\section{PIERRE MORELLI}

Centre de recherche sur les médiations

Université Paul Verlaine-Metz

morelli@univ-metz.fr 